\title{
The Risk and Protective Factors of School Absenteeism
}

\author{
Rajeevan Rasasingham ${ }^{1,2}$ \\ ${ }^{1}$ University of Toronto, Toronto, Canada \\ ${ }^{2}$ Harvard University, Cambridge, MA, USA \\ Email: rajrasas@hotmail.com
}

Received 10 March 2015; accepted 12 April 2015; published 17 April 2015

Copyright (C) 2015 by author and Scientific Research Publishing Inc.

This work is licensed under the Creative Commons Attribution International License (CC BY). http://creativecommons.org/licenses/by/4.0/

(c) (i) Open Access

\begin{abstract}
Absenteeism from school in children and adolescents is a problem that impacts the social, emotional and educational development of the children (Haarman, 2011). While absenteeism can be seen as a short-term condition, prolonged absenteeism during childhood may be a predictor of lasting issues that may persist into adulthood (King, Ollendick and Tonge, 1995), such as "school dropout, delinquency and occupational and relationship problems" (Kearney and Bensaheb, 2006), and economic deprivation and social, marital, occupational and psychiatric problems (Kearney and Graczyk, 2014). Early absenteeism has been associated with school dropout, further disconnecting the children from school based health programs and leading the children into economic deprivation, and marital, social and psychiatric problems in adulthood (Kogan, Luo, Murry and Brody, 2005). Furthermore, absenteeism may be an indication of "suicide attempt, perilous sexual behaviour, teenage pregnancy, violence, unintentional injury, driving under the influence of alcohol, and alcohol, marijuana, tobacco, and other substance abuse" (Kearney, 2008). The purpose of this article is to provide a review of the literature on protective and risk factors for school absenteeism in youths aged 5 to 18 years old, with focus on articles published after 2004. First, the definition of absenteeism will be discussed, followed by the prevalence and demographic of this phenomenon, the protective and risk factors of school absenteeism, and a review of intervention strategies.
\end{abstract}

\section{Keywords}

School Absenteeism, Child and Adolescent Psychiatry and Review

\section{Introduction}

Absenteeism from school in children and adolescents is a problem that impacts the social, emotional and educa-

How to cite this paper: Rasasingham, R. (2015) The Risk and Protective Factors of School Absenteeism. Open Journal of Psychiatry, 5, 195-203. http://dx.doi.org/10.4236/ojpsych.2015.52023 
tional development of the children [1]. While absenteeism can be seen as a short-term condition, prolonged absenteeism during childhood may be a predictor of lasting issues that may persist into adulthood [2], such as "school dropout, delinquency and occupational and relationship problems" [3] and economic deprivation and social, marital, occupational and psychiatric problems (Kearney and Graczyk, 2014).

Early absenteeism has been associated with school dropout, further disconnecting the children from school based health programs and leading the children into economic deprivation, and marital, social and psychiatric problems in adulthood [4]. Furthermore, absenteeism may be an indication of "suicide attempt, perilous sexual behaviour, teenage pregnancy, violence, unintentional injury, driving under the influence of alcohol, and alcohol, marijuana, tobacco, and other substance abuse" [5].

The purpose of this article is to provide a review of the literature on protective and risk factors for school absenteeism in youths aged 5 to 18 years old with focus on articles published after 2004. First, the definition of absenteeism will be discussed, followed by the prevalence and demographic of this phenomenon, the protective and risk factors to school absenteeism, and a review of intervention strategies.

\section{Definition}

Literature on school absenteeism dates back to 1932 when Broadwin characterized some children to exhibit a set of behaviors in refusing school that "are an attempt to obtain love, or escape from real situations to which it is difficult to adjust" [6]. The early definitions of absenteeism were clinically driven, mostly anxiety and schoolphobia based. Later on, school phobia was seen to be too psychopathological, so the alternative term school refusal behavior was used to describe the broader phenomena [7].

Absenteeism, defined by Kearny, refers to a legitimate or illegitimate absence from school or class. Legitimate reasons for missing school include illnesses, religious holidays, the need to attend a family funeral, hazardous weather conditions, and exemptions for college attendance or specific kinds of work [8].

School refusal behavior refers to a child-motivated refusal to attend school [9]. This is different from truancy, which is defined as unexcused and unlawful absence from school without parental knowledge and consent [10]. The truant child usually "conceals absences from his or her parents" [11].

This article focuses mainly on "absenteeism" as school refusal behavior, a parentally known behavior of the child. Occasionally, truancy will also be discussed where its risk and protective factors are similar to a child with school refusal behavior.

\section{Prevalence}

School absenteeism is prevalent. In 2012, the estimated American national rate for students missing 21 days of school is 10 percent [12]. This estimates to roughly 5 to 7.5 million students not attending school regularly in grades pre-kindergarten to grade 12 in America's public schools [12].

Absenteeism such as morning misbehaviors and school-based distress add up to $28 \%-35 \%$ of students in America [8] [13]. A longitudinal study showed that 25\% to $90 \%$ of youth aged 9 to 16 years old who were absent from school met the criteria for a diagnosis from the Diagnostic and Statistical Manual of Mental Disorders, Fourth Edition (DSM-IV; American Psychiatric Association, 1994) [14].

\section{Risk and Protective Factors Related to Absenteeism}

It is important to understand the risk and protective factors of school absenteeism in a contextual way by considering the co-occurrence of different factors [15]. The risk and protective factors related to absenteeism are discussed next.

\subsection{Individual Psychiatric and Physical Conditions}

Children and adolescents with school absenteeism are more likely to have anxiety disorders, affective disorders, disruptive disorders, substance abuse, or a combination of these compared to students without school absenteeism [5] [15]-[17]. However, there is also a number of youth having school refusal behavior or school absenteeism with no diagnosis of a psychiatric illness [5] [15].

Other somatic conditions that are linked to school absenteeism are asthma, headache, stomachache, nausea, vomiting, fatigue, sweating, lightheadedness, abdominal or back pain, heart palpitations, diarrhea, shortness of 
breath and menstruation symptoms [5].

Rumberger and Larson also suggested a pattern in which a student did worse academically when absent more from school. In return, the student felt less motivated to attend school because of the poor academic performance (1998). This cycle shows the beginning of academic disengagement [18].

\subsection{School Climate}

Perceptions of an unsafe school environment, inadequate peer and teacher support [19], inconsistent rules (Stickney and Miltenberger, 1998) and low school connectedness (Shochet et al., 2006) pose as risk factors to school absenteeism. On the other hand, a positive school climate with constructive student-teacher relationship is seen as protective factors against low attendance and drop-out rates [20].

A more recent study by Havik, Bru and Ertsevag shows similar findings. Havik et al.'s study suggests that noisy, disruptive and unpredictable classrooms pose as challenges to children (2013). In such environments, teachers spend more time calming the disruptions than in giving attention to more vulnerable students, which further increases the risk of school refusal [21]. Overall, students have a need for predictability and the feeling of being valued. Havik et al. argues that these are interconnected factors in creating a predictable learning situation (2013). To create such a predictable learning situation, Havik et al. emphasize for teachers to manage student behavior and provide emotional support, as well as the need in more knowledge of school refusal behavior to earlier identify the problem (2013).

\subsection{Family Connectedness and Involvement}

There has been well-established literature on family involvement as a protective factor from school truancy and absenteeism [22], with literature dating back to 1994 stating family-relationship factors having a positive correlation with truancy [23]. Variables include the family's socioeconomic status, the family's attitude towards education, parental knowledge of truancy, parental situations, parenting skills, child abuse and neglect [10].

Contrarily, risk factors of school absenteeism include crowded living conditions, weak parent-child relationships, frequent relocation, and low-income families [24]. One study shows that weak parental supervision poses as a key risk factor for problematic absenteeism [15] [25] [26].

Parental involvement for enhancing academic socialization has been supported more recently [27]. Hill and Tysons' study highlighted the significant role of families, family-school relations, and parental involvement in education to have positive associations with achievement in early adolescence. Their study also states that without effective parental involvement, the child's opportunities are limited, "leading to lost potential, unrealized talent, diminished educational and vocational attainment, and widening demographic gaps in achievement” [27].

\subsection{Family Structure and Functioning}

Children with teenage unmarried mothers are more likely to be chronically absent in elementary school [28]. As well, children who are homeless or have unstable housing situations are more likely to be absent from school [29]. McShane et al. shows that adolescents with school refusal behavior may be in separated families (21\%) in families with conflicts (43\%) (2001).

Adolescents with high levels of behavior problems and absenteeism were more likely to change schools [18].

School refusing adolescents may also have mothers $(53 \%)$ or fathers $(34 \%)$ with psychiatric illnesses in the family [17]. Other factors related to increased absenteeism are alcoholism in parents [30]. Children with parents who work nonstandard shifts (nights/weekends) may need to be more reliant on themselves, which may result in greater chance of absences [31].

\subsection{Neighborhood and Community Factors}

Wandersman and Nation's study shows that mental health outcomes are related to neighborhood characteristics such as the socioeconomic status, racial and ethnic composition, residential patterns and family disruption, social incivilities (public drunkenness, corner gangs, street harassment, drug trade) and physical incivilities (abandoned buildings, vandalism, litter, dilapidated housing) [1998]. In low-income neighborhoods, children may attend poorly funded schools, be exposed to acts of violence, experience maltreatment, and parents and teachers may have infrequent contact (Wandersman and Nation, 1998) [22]. 
More than a decade later, findings continue to support this by studying neighbor characteristics. Gottfried's study shows that higher levels of neighbor poverty, higher number of average neighbor household size, younger average neighbor age, neighbor home ownership, and greater percentage of Black neighbors in the student's residential block to be predictors of student absences [32] [33]. As students may not interact "on a sustained basis" with those employed, students exposed to areas of high levels of poverty may not see the value of education, resulting in a downward cycle of low expectations and low achievement [34].

Contrarily, youth and parents in affluent communities have more access to support systems and resources. Areas of greater neighbor homeownership have shown to have greater residential stability and larger neighbor social networks [35]. As well, increased homeownership may directly decrease neighborhood block crime, leading to improved schooling outcomes [36].

\subsection{Ethnic Minority Status}

In comparing White students with Black students, White students have been positively correlated with excused absences and negatively with unexcused absences [7]. Black students are more likely to have unexcused absences and less likely to have excused absences [7]. According to Gottfried, Asian students are less likely to have number of days absent (2009). As well, when compared to non-Asian children, White and Asian children are less often to be chronically absent in kindergarten and first grade children [37]. Children who missed more than 10 days of kindergarten and first grade were more likely to have English as a second language [37].

Benner and Graham also show that Latino adolescents report increased discrimination in the first two years of high school (2011). Perception of the school climate by the Latino adolescent indirectly affects the adolescents' grades and absences negatively [38].

Bayer and McMillian showed that neighborhoods with predominantly Black residents have less access to amenities and services (2005). Moreover, neighborhood sorting results in the decline of social capital, social services, and community resources (Bayer \& McMillian, 2005).

The location of a neighborhood affects the youth's health, which in turn affects absenteeism. One example used is the rate of childhood asthma due to the environmental factors, further affecting absenteeism. Neighborhoods in chemically toxic areas or closer to hazardous waste sites are also neighborhoods with higher percentage of minority residents. In such neighborhoods, children are more exposed to the toxic environments [39]. Other studies have shown that stressors associated with poverty, family dysfunction, and neighborhood conditions may contribute to asthma, resulting in missed school days [40].

\subsection{Sexual Minority Status}

Burton, Marshal and Chisolm's study reported more excused and unexcused absences were found in sexual minority youth aged 14 to 19 compared to heterosexual youth (2014). This study also suggests that absences from school "may be an early warning sign for mental health issues, particularly in sexual minority youth" [41].

In Kosciw and Diazs' studies, sexual minority youth were youth who self-identified as a lesbian, gay, bisexual and transgender (LGBT) youth. Sexual minority youth often report experiencing violence and discrimination, resulting in higher rates of absenteeism, discipline problems, and low academic achievement [7] [42] due to feeling unsafe and uncomfortable at school [43] [44]. Violence includes experiences of verbal and physical harassment and assault [45], sexual harassment [46], social exclusion and isolation [47], and other interpersonal problems with peers [48] [49].

The most common reason youth reported for being bullied or harassed was because of the way they looked or their body size, followed by the self-identification or being perceived as lesbian, gay or bisexual [50]. Harris Interactive and GLSEN also reported that LGBT students (22\%) were more likely than non-LGBT students (7\%) to feel unsafe at school (2005). Supporting other previous studies, Harris Interactive and GLSEN's report also showed that experiences of violence and feeling unsafe at school were linked to poor academic performances, due to higher rates of absenteeism (missing classes and skipping school days) (2005).

Another study suggests that schools with low homophobic teasing and positive school climate reduce the prevalence of negative outcomes in LGB youth, such as drug use, depression, suicidality and truancy [51].

Unsafe school climates specific to sexual minority youth were more so in rural communities, whereas larger urban schools labeled as the most "dangerous" may actually provide safer environments for sexual minority youth [43]. Goodenow et al. [52] provides an explanation by suggesting that larger urban schools may have a 
more diverse climate, allowing for students to have a sense of belonging in identifying with more diverse social "niches" (2006).

\section{Intervention}

Intervention strategies for children and youth with absenteeism ranges from clinically and medically focused, school climate improvements, family based to systemic changes.

\subsection{Clinically and Medically Focused: Cognitive Behavioral Therapy}

Studies have shown the effectiveness of cognitive-behavioral therapy (CBT) for anxiety-based school refusal due to "the role of self-efficacy in mediating the outcome of CBT for school refusal" [53].

Aside from anxiety-based school absenteeism, Kearny also identified non-anxiety based cases of absenteeism for children aged 5 to 17 years old. Non-anxiety based cases are identified into two functions: refusing school to pursue attention from significant others, and refusing school to pursue tangible rewards outside of school. For cases of absenteeism based on non-anxiety cases, Kearney suggests more parent-based involvement by setting morning routines and providing attention-based consequences (Kearney and Graczyk, 2007). For those refusing school to pursue tangible rewards outside of school, Kearney suggests incentives for attendance and disincentives for nonattendance (Kearney and Graczyk, 2007)

Away from anxiety-based and non-anxiety based cases of absenteeism, other studies have shown interventions to target low self-esteem, social skills and medical conditions. A variety of interventions on the medical and individual level have been suggested, such as individual therapy, social-service referrals, hand-washing to prevent disease, and asthma prevention strategies [54].

\subsection{School Climate Improvement}

Feeling unsafe in the school environment has been a recurring issue for school absenteeism, especially for ethnic minority and sexual minority youth. Preliminary research has suggested that extracurricular clubs such as Gay Straight Alliances (GSAs) in schools have been successful in improving the school climate for sexual minority youth whether or not they participate in the club [55] [56].

Positive Behavioral Interventions and Supports (PBIS) is a whole-school prevention model that aims to modify school climate by promoting positive change in staff and student behaviors. Research has shown that school organizational health is positively associated with student performance and negatively associated with absenteeism and suspensions [57]. Kearney and Bates suggest that the homeroom or classroom teacher may be used to identify students at risk of absenteeism and to inform parents and other school officials of absences (2005).

\subsection{Parental Involvement}

Decades of studies show the powerful influence of parents and family members on student achievement (Galindo and Sheldon, 2012). Strategies have been developed to increase parental involvement in school, family, and community partnerships [22].

One study examined the significance of school partnership programs in helping families create supportive home environments, increase parent-school communication, recruit parents to help at school and serve on school committees, and provide information to families about how to help students with homework and integrate community-based resources to strengthen school programs [58]. This study showed that schools that had implemented this partnership program had significantly greater student attendance than schools that did not [58]. As well, schools' effort in engaging families have shown lower levels of chronic absenteeism and lower levels of student behavior problems [59].

As called to attention by Pina et al. [13], an important part of successfully implementing an intervention is the collaboration between school officials, parents, youth and others responsible for the youth's treatment to share a similar concept of the problem. In collaborating, the young person's chance of reversing to negative school refusal behavior is limited, with the help of the staff at school to monitor school attendance, and the youth to feel secure when at school [13]. As well, Schorr [60] states components of a successful program that successfully engages with parents to include 
"the ability to be comprehensive, responsive, and flexible; view children in their family context; understand that families are an integral part of neighborhoods and communities; operate and maintain long-term preventive measures; appoint highly trained staff and competent management with clearly identifiable skills; ensure ongoing training; and establish mutual trust and collaboration among practitioners” (1997).

\subsection{Putting It All Together: A Holistic Approach}

It is important to understand where each student stands in his or her severity in school absenteeism. Kearny and Graczyk (2013)'s Response to Intervention model distinguishes problematic school absenteeism into three tiers of increasing intervention intensity: universal intervention, targeted intervention (emerging absenteeism, 25\% $35 \%$ of students) and intensive intervention (severe absenteeism, $5 \%-10 \%$ of students).

Intervention strategies are used differ based on the student's severity. In the tier 1 universal intervention approach, all students are involved in regular screening to promote attendance and to begin to identify students who may not be benefitting from the core strategies (Kearney and Graczyk, 2013). Such strategies include school climate strategies, safety-oriented strategies, health-based strategies, character education, parental involvement, orientation activities, summer bridge and school readiness programs, culturally responsive approaches and policy review may be used (Kearney and Graczyk, 2013).

Tier 2 intervention is a more targeted strategy, in which at-risk students are identified to begin setting goals, parent collaboration, and adjunctive supports (Kearney and Graczyk, 2013). Last but not least, Tier 3 interventions hone in on students with "complex or severe problems who require a concentrated approach and frequent progress monitoring” (Kearney and Graczyk, 2013), which may include a more innovative approach and an expansion from Tier 2 strategy. Tier 3 strategy may include alternative educational programs, legal strategies, or multisystemic therapy (Kearney and Graczyk, 2013).

\section{Conclusion}

This review of literature has shown development in more recent understanding of the risk and protective factors in children and adolescents with school absenteeism difficulties. What is important though is the early identification of at-risk students of absenteeism and school refusal behaviour in the school setting. Only one party cannot tackle school absenteeism. Rather, coordination and collaboration between different agencies, such as family members, school officials, social workers, mental health professionals, criminal justice and research, must happen to effectively work together to prevent and work with children and adolescents with school absenteeism.

\section{References}

[1] Haarman, G.B. (2011) School Refusal Behaviour: Children Who Can’t or Won’t Go To School. Education and Consultation Press, Louisville.

[2] King, N.J., Tonge, B.J. and Ollendic, T.H. (1995) School Refusal: Assessment and Treatment. Allyn \& Bacon, Boston.

[3] Kearney, C.A. and Bensaheb, A. (2006) School Absenteeism and School Refusal Behaviour: A Review and Suggestions for School-Based Health Professionals. Journal of School Health, 76, 3-7. http://dx.doi.org/10.1111/j.1746-1561.2006.00060.x

[4] Kogan, S.M., Luo, Z.P., Murry, V.M. and Brody, G.H. (2005) Risk and Protective Factors for Substance Use among African American High School Dropouts. Psychology of Addictive Behaviors, 19, 382-391. http://dx.doi.org/10.1037/0893-164X.19.4.382

[5] Kearney, C.A. (2008) School Absenteeism and School Refusal Behaviour in Youth: A Contemporary Review. Clinical Psychology Review, 28, 451-471. http://dx.doi.org/10.1016/j.cpr.2007.07.012

[6] Broadwin, I.T. (1932) A Contribution to the Study of Truancy. American Journal of Orthopsychiatry, 2, 253-259. http://dx.doi.org/10.1111/j.1939-0025.1932.tb05183.x

[7] Grossman, A.H., Haney, A.P., Edwards, P., Alessi, E.J., Ardon, M. and Howell, T.J. (2009) Lesbian, Gay, Bisexual and Transgender Youth Talk about Experiencing and Coping with School Violence: A Qualitative Study. Journal of LGBT Youth, 6, 24-46. http://dx.doi.org/10.1080/19361650802379748

[8] Kearney, C.A. (2001) School Refusal Behaviour in Youth: A Functional Approach to Assessment and Treatment. American Psychological Association, Washington DC. http://dx.doi.org/10.1037/10426-000

[9] Kearney, C.A. (1996) The Evolution and Reconciliation of Taxonomic Strategies for School Refusal Behavior. Clinical Psychology: Science and Practice, 3, 339-354. http://dx.doi.org/10.1111/j.1468-2850.1996.tb00087.x 
[10] Bell, A.J., Rosen, L.A. and Dynlacht, D. (1994) Truancy Intervention. Journal of Research and Development in Education, 27, 203-211.

[11] Lee, M.I. and Miltenberger, R.G. (1996) School Refusal Behaviour: Classification, Assessment, and Treatment Issues. Education and Treatment of Children, 19, 474-486.

[12] Balfanz, R. and Byrnes, V. (2012) Chronic Absenteeism: Summarizing What We Know from Nationally Available Data. Johns Hopkins University, Baltimore.

[13] Pina, A.A., Zerr, A.A., Gonzales, N.A. and Ortiz, C.D. (2009) Psychosocial Interventions for School Refusal Behaviour in Children and Adolescents. Child Development Perspectives, 3, 11-20. http://dx.doi.org/10.1111/j.1750-8606.2008.00070.x

[14] Egger, H.L., Costello, E.J. and Angold, A. (2003) School Refusal and Psychiatric Disorders: A Community Study. Journal of the American Academy of Child \& Adolescent Psychiatry, 42, 797-807. http://dx.doi.org/10.1097/01.CHI.0000046865.56865.79

[15] Ingul, J.M., Klockner, C.A., Silverman, W.K. and Nordahl, H.M. (2012) Adolescent School Absenteeism: Modelling Social and Individual Risk Factors. Child and Adolescent Mental Health, 17, 93-100. http://dx.doi.org/10.1111/j.1475-3588.2011.00615.x

[16] Kearney, C.A. and Albano, A.M. (2004) The Functional Profiles of School Refusal Behaviour: Diagnostic Aspects. Behaviour Modification, 28, 147-161. http://dx.doi.org/10.1177/0145445503259263

[17] McShane, G., Walter, G. and Rey, J.M. (2001) Characteristics of Adolescents with School Refusal. Australian and New Zealand Journal of Psychiatry, 35, 822-826. http://dx.doi.org/10.1046/j.1440-1614.2001.00955.x

[18] Rumberger, R.W. and Larson, K.A. (1998) Student Mobility and the Increased Risk of High School Dropout. American Journal of Education, 107, 1-35. http://dx.doi.org/10.1086/444201

[19] Way, N., Reddy, R. and Rhodes, J. (2007) Students’ Perceptions of School Climate during Middle School Years: Associations with Trajectories of Psychological and Behavioural Adjustment. American Journal of Community Psychology, 40, 194-213. http://dx.doi.org/10.1007/s10464-007-9143-y

[20] Brookmeyer, K.A., Fanti, K.A. and Henrich, G.C. (2006) Schools, Parents, and Youth Violence: A Multilevel, Ecological Analysis. Journal of Clinical Child and Adolescent Psychology, 35, 504-514. http://dx.doi.org/10.1207/s15374424jccp3504_2

[21] Havik, T., Bru, E. and Ertesvag, S.K. (2013) Parental Perspectives of the Role of School Factors in School Refusal. Emotional \& Behavioural Difficulties, 19, 131-153. http://dx.doi.org/10.1080/13632752.2013.816199

[22] Teasley, M.L. (2004) Absenteeism and Truancy: Risk, Protection and Best Practice Implications for School Social Workers. Children \& Schools, 26, 117-126. http://dx.doi.org/10.1093/cs/26.2.117

[23] Kleine, P.A. (1994) Chronic Absenteeism: A Community Issue. National Centre for Research on Teacher Learning, East Lansing.

[24] Thornberry, T.P., Smith, C.A., Rivera, C., Huizinga, D. and Stouthamer-Loeber, M. (1999) Family Disruption and Delinquency. National Centre for Research on Teacher Learning, East Lansing.

[25] Reid, K. (2005) The Causes, Views and Traits of School Absenteeism and Truancy: An Analytical Review. Research in Education, 74, 59-82. http://dx.doi.org/10.7227/RIE.74.6

[26] Kearney, C.A. (2008) An Interdisciplinary Model of School Absenteeism in Youth to Inform Professional Practice and Public policy. Educational Psychology Review, 20, 257-282. http://dx.doi.org/10.1007/s10648-008-9078-3

[27] Hill, N.E. and Tyson, D.F. (2009) Parental Involvement in Middle School: A Meta-Analytic Assessment of the Strategies That Promote Achievement. Developmental Psychology, 45, 740-763. http://dx.doi.org/10.1037/a0015362

[28] Romero, M. and Lee, Y. (2008) The Influence of Maternal and Family Risk on Chronic Absenteeism in Early Schooling. National Centre for Children in Poverty, Columbia University, New York.

[29] Rafferty, Y. (1995) The Legal Rights and Education Problems of Homeless Children and Youth. Educational Evaluation and Policy Analysis, 17, 39-61. http://dx.doi.org/10.3102/01623737017001039

[30] Casas-Gil, M.J. and Navarro-Guzman, J.I. (2002) School Characteristics among Children of Alcoholic Parents. Psychological Reports, 90, 341-348. http://dx.doi.org/10.2466/pr0.2002.90.1.341

[31] Han, W.-J. (2005) Maternal Nonstandard Work Schedules and Child Outcomes. Child Development, 76, 137-154. http://dx.doi.org/10.1111/j.1467-8624.2005.00835.x

[32] Gottfried, M.A. (2009) Excused versus Unexcused: How Student Absences in Elementary School Affect Academic Achievement. Education Evaluation and Policy Analysis, 31, 392-415. http://dx.doi.org/10.3102/0162373709342467

[33] Gottfried, M.A. (2014) Can Neighbor Attributes Predict School Absences? Urban Education, 49, 216-250. http://dx.doi.org/10.1177/0042085913475634 
[34] Jargowsky, P.A. and El Komi, M. (2009) Before or After the Bell? School Context and Neighborhood Effects on Student Achievement. Calder Working Paper No. 28, National Centre for Analysis of Longitudinal Data in Education Research, Washington DC.

[35] Dietz, R. and Haurin, D.R. (2003) The Private and Social Micro-Level Consequences of Homeownership. Journal of Urban Economics, 54, 401-450. http://dx.doi.org/10.1016/S0094-1190(03)00080-9

[36] Sharkey, P. (2010) The Acute Effect of Local Homicides on Children's Cognitive Performance. Proceedings of the National Academy of Sciences of the United States of America, 107, 11733-11738. http://dx.doi.org/10.1073/pnas.1000690107

[37] Ready, D.D. (2010) Socioeconomic Disadvantage, School Attendance, and Early Cognitive Development: The Differential Effects of School Exposure. Sociology of Education, 83, 271-286. http://dx.doi.org/10.1177/0038040710383520

[38] Benner, A.D. and Graham, S. (2011) Latino Adolescents' Experiences of Discrimination Across the First 2 Years of High School: Correlates and Influences on Educational Outcomes. Child Development, 82, 508-519. http://dx.doi.org/10.1111/j.1467-8624.2010.01524.x

[39] Berliner, D.C. (2009) Poverty and Potential: Out-of-School Factors and School Success. Education and the Public Interest Centre \& Education Policy Research Unit, Boulder and Tempe.

[40] Bryant-Stephens, T. (2009) Asthama Disparities in Urban Environments. Journal of Allergy and Clinical Immunology, 123, 1199-1206. http://dx.doi.org/10.1016/j.jaci.2009.04.030

[41] Burton, C.M., Marshal, M.P. and Chisolm, D.J. (2014) School Absenteeism and Mental Health among Sexual Minority Youth and Heterosexual Youth. Journal of School Psychology, 52, 37-47. http://dx.doi.org/10.1016/j.jsp.2013.12.001

[42] Kosciw, J. and Diaz, E. (2006) 2005 National School Climate Survey: The Experiences of Lesbian, Gay, Bisexual and Transgender Youth in Our Nation’s Schools. Gay, Lesbian and Straight Education Network, New York.

[43] Kosciw, J., Greytak, E. and Diaz, E. (2009) Who, What, Where, When and Why: Demographic and Ecological Factors Contributing to Hostile School Climate for Lesbian, Gay, Bisexual and Transgender Youth. Journal of Youth and Adolescence, 28, 976-988. http://dx.doi.org/10.1007/s10964-009-9412-1

[44] McGuire, J.K., Anderson, C.R., Toomey, R.B. and Russell, S.T. (2010) School Climate for Transgender Youth: A Mixed Method Investigation of Student Experiences and School Responses. Journal of Youth and Adolescence, 39, 1175-1188. http://dx.doi.org/10.1007/s10964-010-9540-7

[45] Bontempo, D.E. and D’Augelli, A.R. (2002). Effects of At-School Victimization and Sexual Orientation on Lesbian, Gay, or Bisexual Youths' Health Risk Behaviour. The Journal of Adolescent Health, 30, 364-374. http://dx.doi.org/10.1016/S1054-139X(01)00415-3

[46] Bochenek, M. and Brown, A.W. (2001) Hatred in the Hallways: Violence and Discrimination against Lesbian, Gay, Bisexual, and Transgender Students in US Schools. Human Rights Watch, New York.

[47] Ueno, K. (2005) Sexual Orientation and Psychological Distress in Adolescence: Examining Interpersonal Stressors and Social Support Processes. Social Psychology Quarterly, 68, 258-277. http://dx.doi.org/10.1177/019027250506800305

[48] Pearson, J., Muller, C. and Wilkinson, L. (2007) Adolescent Same-Sex Attraction and Academic Outcomes: The Role of School Attachment and Engagement. Social Problems, 54, 523-542. http://dx.doi.org/10.1525/sp.2007.54.4.523

[49] Russell, S.T., McGuire, J.K., Laub, C., Manke, E., O’Shaughnessy, M., Heck, K. and Calhoun, C. (2006) Harassment in School Based on Actual or Perceived Sexual Orientation: Prevalence and Consequences. California Research Brief No. 2, California Safe Schools Coalition, San Francisco.

[50] Harris Interactive and GLSEN (2005) From Teasing to Torment: School Climate in America, a Survey of Students and Teachers. GLSEN, New York.

[51] Birkett, M., Espelage, D.L. and Koenig, B. (2009) LGB and Questioning Students in Schools: The Moderating Effects of Homophobic Bullying and School Climate on Negative Outcomes. Journal of Youth and Adolescence, 39, 9891000. http://dx.doi.org/10.1007/s10964-008-9389-1

[52] Goodenow, C., Szalacha, L. and Westheimer, K. (2006) School Support Groups, Other School Factors, and the Safety of Sexual Minority Adolescents. Psychology in the Schools, 43, 573-589. http://dx.doi.org/10.1002/pits.20173

[53] Maric, M., Heyne, D.A., MacKinnon, D.P., van Widenfelt, B.M. and Westenburg, P.M. (2012) Cognitive Mediation of Cognitive-Behavioural Therapy Outcomes for Anxiety-Based School Refusal. Behavioural and Cognitive Psychotherapy, 41, 549-564. http://dx.doi.org/10.1017/S1352465812000756

[54] Maynard, B.R., McCrea, K.T., Pigott, T.D. and Kelly, M.S. (2012) Indicated Truancy Interventions: Effects on School Attendance among Chronic Truant Students. Campbell Systematic Reviews, 8, 8.

[55] Hatzenbuehler, M.L. (2011) The Social Environment and Suicide Attempts in Lesbian, Gay, and Bisexual Youth. Pediatrics, 127, 896-903. http://dx.doi.org/10.1542/peds.2010-3020 
[56] Walls, N.E., Kane, S.B. and Wisneski, H. (2010) Gay-Straight Alliances and School Experiences of Sexual Minority Youth. Youth \& Society, 41, 307-332. http://dx.doi.org/10.1177/0044118X09334957

[57] Bradshaw, C.O., Koth, C.W., Thornton, L.A. and Leaf, P.J. (2009) Altering School Climate through School-Wide Positive Behavioural Interventions and Supports: Findings from a Group-Randomized Effectiveness Trial. Prevention Science, 10, 100-115. http://dx.doi.org/10.1007/s11121-008-0114-9

[58] Epstein, J.L. and Sheldon, S.B. (2002) Present and Accounted for: Improving Student Attendance through Family and Community Involvement. Journal of Educational Research, 95, 308-318. http://dx.doi.org/10.1080/00220670209596604

[59] Sheldon, S.B. (2007) Improving Student Attendance with School, Family, and Community Partnerships. The Journal of Educational Research, 100, 267-275. http://dx.doi.org/10.3200/JOER.100.5.267-275

[60] Schorr, L.B. (1997) Common Purpose: Strengthening Families and Neighborhoods to Rebuild America. Doubleday, New York. 